Nat. Hazards Earth Syst. Sci., 10, 171-179, 2010 www.nat-hazards-earth-syst-sci.net/10/171/2010/ (C) Author(s) 2010. This work is distributed under the Creative Commons Attribution 3.0 License.

\title{
On analysing sea level rise in the German Bight since 1844
}

\author{
T. Wahl, J. Jensen, and T. Frank \\ Research Institute for Water and Environment, University of Siegen, Germany \\ Received: 27 July 2009 - Revised: 4 January 2010 - Accepted: 17 January 2010 - Published: 1 February 2010
}

\begin{abstract}
In this paper, a methodology to analyse observed sea level rise (SLR) in the German Bight, the shallow southeastern part of the North Sea, is presented. The paper focuses on the description of the methods used to generate and analyse mean sea level (MSL) time series. Parametric fitting approaches as well as non-parametric data adaptive filters, such as Singular System Analysis (SSA) are applied. For padding non-stationary sea level time series, an advanced approach named Monte-Carlo autoregressive padding (MCAP) is introduced. This approach allows the specification of uncertainties of the behaviour of smoothed time series near the boundaries. As an example, the paper includes the results from analysing the sea level records of the Cuxhaven tide gauge and the Heligoland tide gauge, both located in the south-eastern North Sea. For comparison, the results from analysing a worldwide sea level reconstruction are also presented. The results for the North Sea point to a weak negative acceleration of SLR since 1844 with a strong positive acceleration at the end of the 19th century, to a period of almost no SLR around the 1970s with subsequent positive acceleration and to high recent rates.
\end{abstract}

\section{Introduction}

Sea Level Rise (SLR) is one of the major consequences we are facing in times of a warming climate and it is obvious that a higher sea level influences the heights of occurring storm surges and thus results in a higher risk of inundation for the affected coastal areas. Therefore, regional and global sea level rise are subjects to many recent scientific publications (e.g., White et al., 2005; Jevrejeva et al., 2006; Wöppelmann et al., 2006; Holgate, 2007; Church et al., 2008; Woodworth

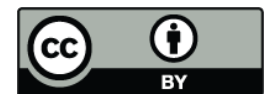

Correspondence to: T. Wahl (thomas.wahl@uni-siegen.de) et al., 2009a, b). In contrast, the mean sea level (MSL) and its variability over the last centuries in the German North Sea area have not been analysed in detail up to now. This is surprising, because many long and continuous sea level time series are available (Wahl et al., 2008). Some studies considered time series from a very small number of tide gauges and high resolution data sets have not been used or not been available (e.g. Dietrich, 1954; Jensen and Mudersbach, 2007). Furthermore, various projects dealing with mean tidal conditions, e.g. the mean tidal high waters (MHW) or the mean tidal ranges (MTR), have been conducted so far (e.g., Führböter and Jensen, 1985; Töppe and Brockmann, 1992; Gönnert et al., 2004). Most of the available sea level records consist of high and low water heights and times (from here on referred to as high and low waters), which are not directly applicable for MSL analyses. The simple averaging of high and low waters leads to the mean tide level (MTL) and not to the MSL. The latter can be estimated by averaging high resolution sea level data consisting of at least hourly measurements. The difference between MSL and MTL is small in most areas (e.g., Pugh, 2004; Wöppelmann et al., 2006), but up to more than $20 \mathrm{~cm}$ along the German North Sea coastline due to shallow water effects (Lassen, 1989). This has to be considered when generating and analysing mean sea level time series. In addition, some differences between observations and model results, often referred to as "negative sea level budget" (e.g., Church et al., 2008), have not been completely understood up to now. All the more important is the proper analysis of available data sets from tide gauges and in the recent past also from satellites.

The present paper has three main objectives. The first one is to introduce a method which is easy to apply to combine MSL and MTL data. The second one is to introduce an advanced method for padding or extrapolating time series before applying any smoothing technique to find the optimal fit. The third one is to analyse sea level records from two tide gauges in the German North Sea. 
To address the first objective, a modification of the so called k-factor method is introduced in Sect. 2 (Lassen, 1989; Lentz, 1879; Wahl et al., 2008). This modification allows the consideration of non-stationarities in k-factor time series, where the k-factor is subsequently used to convert MTL to MSL. Based upon the resulting MSL time series, long-term trend estimations are possible and smoothing techniques can be applied without leading to gaps. The latter usually occurs, if time series consisting of MSL and MTL data are analysed without applying any methods to combine both variables. In addition, a shift of up to more than $20 \mathrm{~cm}$ somewhere in the time series certainly leads to significant errors and misinterpretations when performing long-term trend estimations. It is worth noting that sea level time series from the German North Sea area show high variability because the major part of the sea level is influenced by stochastic meteorological processes (Müller-Navarra and Giese, 1999). Therefore, it is not always possible to detect shifts of ten to twenty centimetres just by looking at the time series.

As mentioned above, the second objective of the paper is to introduce an advanced method for padding time series before applying any smoothing technique. Whenever smoothing a time series, one has two opportunities. The first one is to start and stop the smoothing at a specified time (depending on the chosen window length) before reaching the ends of the original time series. For example a moving average with a window length of 19 years usually starts 9 years later than the original time series and ends 9 years earlier. The second opportunity, which is increasingly applied in combination with the analysis of climate time series, is to find some meaningful extrapolation from a physical point of view, before applying any smoothing technique. This enables the smoothed time series to cover the same period as the original time series. The method presented in this paper, namely MonteCarlo autoregressive padding (MCAP), results in a very data adaptive smooth and allows the specification of uncertainties near the boundaries due to the padding. Especially the latter is not the case with any other common techniques (e.g., Ghil et al., 2002; Mann, 2004; Jevrejeva et al., 2006; Jansen et al., 2007; Trenberth et al., 2007; Mann, 2008). But, to understand recent SLR and to find projections for the near future, especially the behaviour of the time series near the posterior boundary is important.

The third objective is addressed by presenting the results from analysing sea level records from two important tide gauges in the German North Sea. The Cuxhaven tide gauge provides the longest record with data since 1844. The Heligoland tide gauge provides high quality data due to its exposed location (see Sect. 2). In a further step, the results from analysing the North Sea sea level time series are compared to global patterns of SLR derived from analysing a global sea level reconstruction. The results contribute to the verification of regional climate models and provide indications of SLR for regional and local planning issues. This seems to be of special importance. First, the most recent SLR sce- narios published by the Intergovernmental Panel on Climate Change (IPCC) (Meehl et al., 2007) are subject to an extensive scientific discussion. Some authors find hints from observations or semi-empirical models that the scenarios might underestimate future SLR (Rahmstorf, 2007; Rahmstorf et al., 2007; Jevrejeva et al., 2008; Grinsted et al., 2009). It has to be noted, that the results from semi-empirical models, using empirical relationships between temperature and SLR to estimate future projections, are also lively discussed by the scientific community (e.g. Holgate et al., 2007; von Storch et al., 2008). Second, and even more important, it has to be tested whether a significant correlation exists between SLR in the German North Sea region and global SLR.

\section{Data and methods}

Figure 1 shows the location of the Cuxhaven tide gauge and the Heligoland tide gauge in the south-eastern North Sea. The Cuxhaven station is located at the Elbe estuary and provides permanent sea level data from 1844 to 2008. From the beginning of the record until 1918 only high and low waters are available and afterwards high resolution data with at least hourly values. The Heligoland station is installed in the harbour of the island of Heligoland (Rohde, 1990), which is located about 62 kilometres north-westerly of the Elbe Estuary. Due to its exposed location in the deep water, the tide gauge provides almost unaffected sea level measurements and the tide curves are less deformed. High resolution data is provided since 1953, with a period from 1990 to 1999 where only high and low waters are available.

Both data sets were corrected for local datum shifts and for glacial isostatic adjustment (GIA) by considering a rate of land subsidence of $0.34 \mathrm{~mm} \mathrm{a}^{-1}$ for the Cuxhaven sea level time series and of $0.51 \mathrm{~mm} \mathrm{a}^{-1}$ for the Heligoland sea level time series (Peltier, 2004). GIA is a global process in response to large scale changes in the surface mass load resulting from the last deglaciation. The effect of GIA (rebound or subsidence) is usually assumed to be linear, at least over the last couple of hundred years. Other geological effects may also contribute to land subsidence or rebound (e.g. tectonics, volcanic activity, withdraw of natural resources etc.), but GIA is the only one assessable through numerical models. The sum of all the other effects can be measured via GPS, whereas the GPS station should be located near the tide gauge. Such measurements will contribute to the uncertainty reduction in further studies (Schöne et al., 2009) (see also Sect. 4).

To combine the MSL time series resulting from the high resolution data and the MTL time series resulting from the low resolution data, a monthly $\mathrm{k}$-factor time series $k(t)$ is estimated. The dimensionless $\mathrm{k}$-factor is a reference value for the difference between MSL and MTL and calculated for 


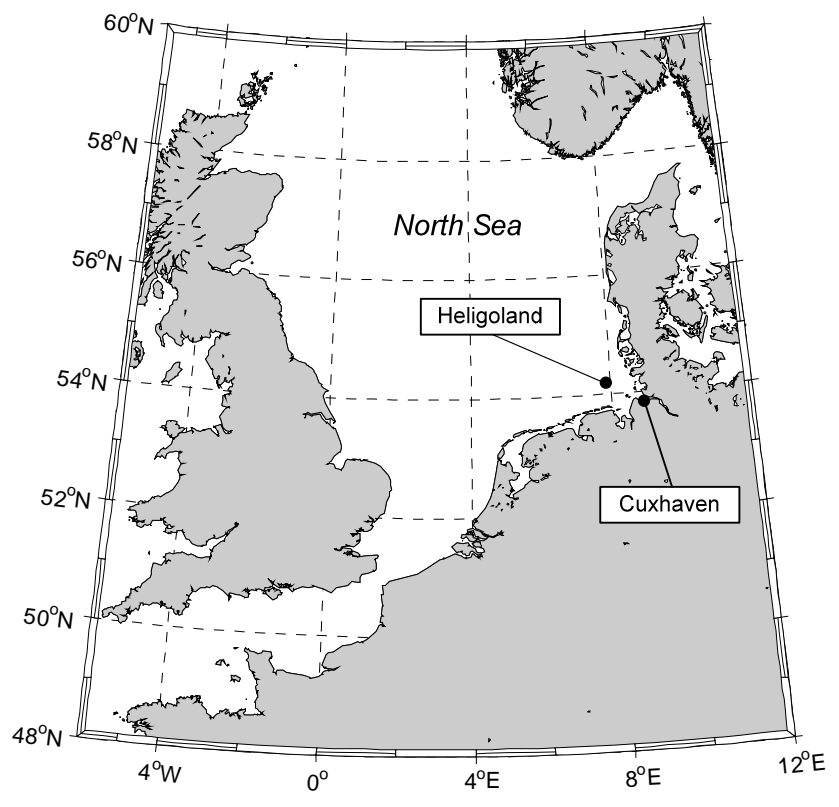

Fig. 1. Locations of the tide gauges Cuxhaven and Heligoland in the south-eastern North Sea.

the time period providing high resolution data using Eq. (1) (Lassen, 1989):

$k(t)=\frac{(\operatorname{MHW}(t)-\operatorname{MSL}(t))}{\operatorname{MTR}(t)}$,

where $\operatorname{MHW}(t)$ is the monthly mean high water, $\operatorname{MSL}(t)$ is the monthly mean sea level and $\operatorname{MTR}(t)$ is the monthly mean tidal range. For the German North Sea coastline, k-factors are found to vary between 0.43 and 0.49 . A $\mathrm{k}$-factor of 0.5 means that the tide curve has a perfect sinusoidal form and that MSL equals MTL.

Before combining MSL and MTL time series, it has to be tested whether the $\mathrm{k}$-factor is a stationary parameter for the investigated gauge station or whether it shows non-stationary behaviour. Therefore, two tests on stationarity are applied to the monthly k-factor time series. The first one is a slidingwindow test with a window length of one year to account for possible seasonality (Mudersbach and Jensen, 2008; van Gelder, 2008). The second test is a two-dimensional nonparametric Kolmogorov-Smirnov test (Chen and Rao, 2002; Mudersbach and Jensen, 2008). If the k-factor is found to be stationary, a monthly MSL time series can be easily estimated with Eq. (2):

$\operatorname{MSL}(t)=\operatorname{MTR}(t) \cdot(0.5-k)+\operatorname{MTL}(t)$,

where $\operatorname{MSL}(t)$ is the monthly mean sea level, $\operatorname{MTR}(t)$ is the monthly mean tidal range, $k$ is the mean $\mathrm{k}$-factor estimated from the time period providing high resolution data and MTL $(\mathrm{t})$ is the monthly mean tide level. If the k-factor shows non-stationary behaviour, a first or higher order polynomial fit has to be applied and extrapolated before correct-

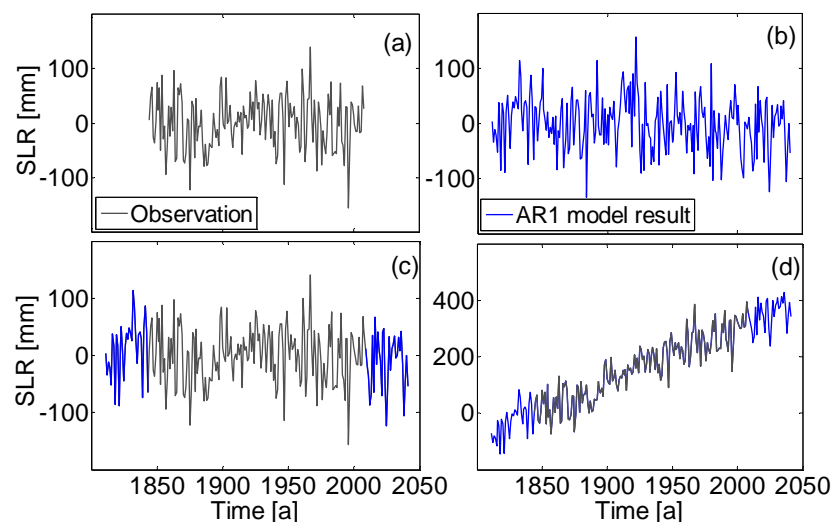

Fig. 2. Steps of MCAP: (a) detrended annual Cuxhaven MSL time series, (b) result of the AR1 Model, two times the chosen embedding dimension longer than the observed time series, (c) padded detrended annual Cuxhaven MSL time series, using the ends of the result of the AR1 model, (d) padded annual Cuxhaven MSL time series with long term-trend of the observed time series re-included. Steps (b) to (d) are repeated 10000 times through Monte Carlo Simulations.

ing MTL values. Equation (3) considers a time dependent k-factor:

$\operatorname{MSL}(t)=\operatorname{MTR}(t) \cdot(0.5-k(t))+\operatorname{MTL}(t)$,

where the variables are the same as in Eq. (2) and $k(t)$ is the time dependent k-factor.

Once a consistent MSL time series has been generated, different methods can be used to analyse the long-term and recent linear and non-linear behaviour. Parametric approaches provide the advantage of allowing extrapolation into the future, whereas data adaptive non-linear methods are valuable to detect inflection points and periods of remarkably high or low rates of SLR.

To analyse MSL time series, the following computational steps are conducted: a first order polynomial function, a second order polynomial function and an exponential function are fitted to the time series. The fit providing the smallest mean-squared error (MSE) is selected and its 95\% confidence bounds are specified. Overlapping decadal rates and relating $95 \%$ confidence bounds are estimated. To determine the non-linear behaviour of the time series, a moving average (MA) and Singular System Analysis (SSA) (Golyandina et al., 2001) are applied. The window length of the MA and the embedding dimension of the SSA are set equal (hereinafter embedding dimension is used to describe both). The default value is $N / 5$, which is the lower boundary value proposed for the embedding dimension by Golyandina et al. (2001) and $N$ is the number of years of observation.

For padding the time series a novel approach named Monte-Carlo autoregressive padding (MCAP) is introduced. MCAP leads to a data adaptive smooth and additionally provides uncertainty assessment for the behaviour of the 
smoothed time series near the boundaries. The first step of MCAP includes the detrending of the original time series (see Fig. 2a) using the first order polynomial fit

$y(t)=\alpha \cdot t+\beta$,

where $\alpha$ represents the linear trend of the time series. In a second step a specified number (default value is 10000) of surrogate data sets is generated (see Fig. 2b) using an AR1 model of the form

$z_{t}=\theta \cdot z_{t-1}+\varepsilon_{t}$,

where $\theta$ is the autocorrelation parameter and $\varepsilon_{t}$ is a white noise process (Box and Jenkins, 1976). The surrogates are two times the chosen embedding dimension longer than the original time series. The first and the last parts (always one time the chosen embedding dimension) of the surrogate data sets are used for padding the detrended original time series (see Fig. 2c). Note, that the ends of the surrogates display more or less strong positive or negative trends. In the last step, the long-term linear trend of the observed time series (see Eq. 4) is re-included (see Fig. 2d). The trend of the padded time series differs slightly from the trend of the original time series. This implies that the long-term trend of the investigated sea level time series will not change dramatically within the next few decades. Figure 2 shows the results of the different steps of MCAP for the Cuxhaven time series. The steps shown in Fig. 2b to Fig. 2d are repeated 10000 times through Monte Carlo Simulations. The result is a set of 10000 surrogates. The latter are two times the chosen embedding dimension (or as default: two times $N / 5$ ) longer than the original time series and show varying long-term trends due to the padding.

For SSA reconstruction, those empirical orthogonal functions (EOFs) providing trend information have to be identified. Therefore, Kendalls $\tau$ (Mann, 1945) is estimated and the same tests on stationarity as mentioned above (slidingwindow test and Kolmogorov-Smirnov test) are applied. Once the EOFs providing trend information are isolated, they are used for reconstruction. To measure the misfit of the reconstructions, the MSE is estimated again. When analysing sea level time series, especially in times of climate change, the behaviour of the time series near the posterior boundary is of special importance. Hence, the reconstruction providing the smallest MSE for the last part of the time series (one time the chosen embedding dimension) is assumed to be the best fit and clearly marked in the resulting plot. All the other reconstructions are represented by a shaded band and provide uncertainty assessment for the smoothed time series near the boundaries. This information seems valuable, because the a priori assumption that future sea level will provide a small MSE is weak. The "true" smooth near the posterior boundary can be estimated in the future, when longer data sets are available. For example, using SSA with an embedding dimension of 33 years means that the "true" smooth for the period from 1844 to 2008 can be estimated at first in 2040 .

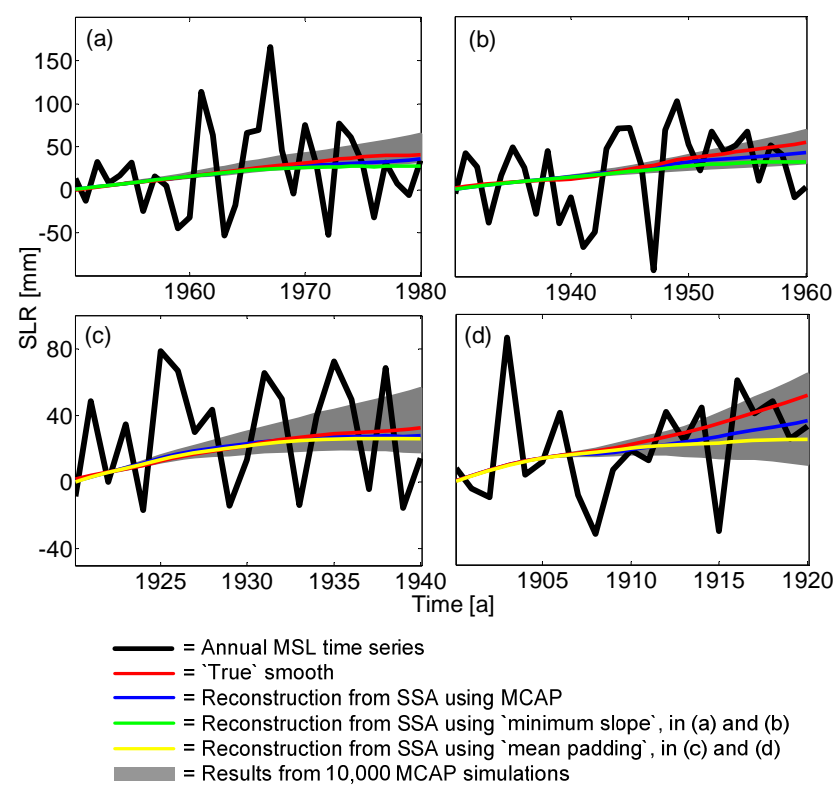

Fig. 3. Comparison of different methods for padding time series. Results are shown for the posterior boundary of truncated intervals of the annual MSL time series of the Cuxhaven gauge station: (a) the 1844 to 1980 interval, (b) the 1844 to 1960 interval, (c) the 1844 to 1940 interval and (d) the 1844 to 1920 interval.

The tide gauge records from Cuxhaven and Heligoland are used here to represent patterns of SLR in the German North Sea area. This seems to be justified, because both stations play an important role for sea level observation in the German North Sea and different authors proved that a very small number of long and high-quality tide gauge records capture the variability found from a considerably larger number of stations (e.g., Holgate, 2007). To compare the estimated patterns of SLR for the North Sea area to global patterns of SLR, a worldwide sea level reconstruction published by Church and White (2006) is analysed using the presented methods. A recently updated version of the reconstruction, providing data from 1870 to 2007 , is available from the homepage of the Permanent Service of Mean Sea Level (PSMSL).

\section{Results}

Before the results from both, the selected sea level time series from the North Sea and the worldwide sea level reconstruction are presented in detail, the efficiency of the MCAP approach is demonstrated. Figure 3 shows the results for truncated intervals of the Cuxhaven annual MSL time series. The estimated smooth providing the smallest MSE, the results from 10000 MCAP simulations and the "true" smooth are calculated and compared in the figure. In addition, two simpler approaches for padding climate time series introduced by Mann (2004), namely the "minimum slope" and the "mean padding" approach are included for comparison 


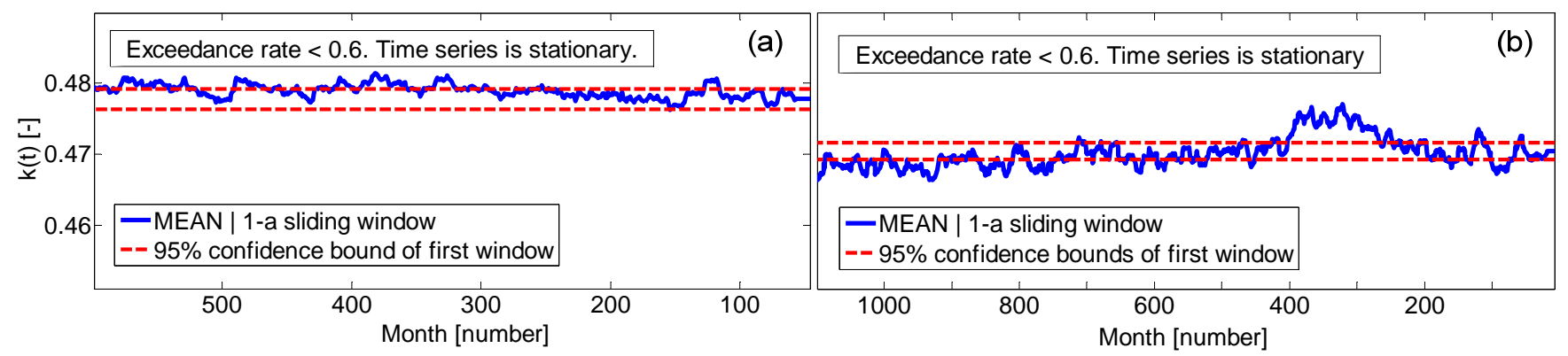

Fig. 4. Results of the sliding-window test on stationarity applied to the monthly k-factor time series of the Heligoland tide gauge (a) and the Cuxhaven tide gauge (b).

purposes. The "minimum slope" approach used in the most recent IPCC assessment (Trenberth et al., 2007) is included in Fig. 3a and b. The "mean padding" approach, also used in the IPCC assessment by Jansen et al. (2007) is included in Fig. 3c and d. Mann (2008) argues that both approaches are tending to artificially suppressing the trends near the boundaries.

The results show that there is always a difference between the estimated and the "true" smoothes. Especially for the 1844 to 1920 interval the "true" smooth clearly suggests a stronger SLR than the estimated smoothes. In addition, a positive acceleration of SLR is indicated by the "true" smooth. The latter is displayed by the MCAP results, whereas the results from using the "mean padding" approach indicate a negative acceleration. The SSA reconstructions using MCAP show better results than the reconstructions using the padding approaches applied in the most recent IPCC assessment in all cases. Only the reconstruction using "minimum slope" for the 1844 to 1980 interval slightly exceeds the shaded band resulting from 10000 MCAP simulations. All the other reconstructions and the "true" smoothes proceed inside the band, which indicates the benefit of the approach. It should be noted, that the application of other methods for padding time series (e.g. Jevrejeva et al., 2006; Rahmstorf et al., 2007; Mann, 2008) lead to better results than the two methods used here for comparison purposes. Especially the "adaptive" approach introduced by Mann (2008) results in a very data adaptive smooth as the name indicates. But neither this one, nor any of the other methods allows the quantification of uncertainties near the boundaries due to the padding.

In the following, the results from analysing the entire record sets of the Cuxhaven tide gauge and the Heligoland tide gauge are presented. Figure 4 shows the results of the sliding-window test on stationarity applied to the monthly kfactor time series. The latter were estimated for the periods providing high resolution data (see Sect. 2). From 20000 Monte-Carlo simulations it was found that exceedance rates of the $95 \%$ confidence bounds of up to $60 \%$ are possible with stationary time series. Thus, both time series are found to be stationary from the sliding-window test as well as from the
Kolmogorov-Smirnov test. The k-factor time series of the Cuxhaven station (Fig. 4b) shows some irregularities at the end of the 1930s and in the 1940s (month numbers 250 to 400), which is probably an effect of the interruption of measures (first of all dredging) in the estuary during and after the Second World War. Former studies suggest that the accuracy of the $\mathrm{k}$-factor improves in proportion to the resolution in time (Wahl et al., 2008). After the k-factor was found to be stationary for both stations, the mean is calculated for the period of 2000 to 2008 for the Heligoland station and for the period of 1998 to 2008 for the Cuxhaven station. Those periods provide sea level data with a resolution in time of one minute. The estimated mean is 0.4783 for the Heligoland station, which equals a difference between MSL and MTL of about $5 \mathrm{~cm}$. The mean k-factor for the Cuxhaven station is estimated to 0.4685 , which equals a difference between MSL and MTL of about $9 \mathrm{~cm}$. The lower k-factor for the Cuxhaven station clearly illustrates that the tide curve is subject to stronger deformations near the coastline due to shallow water effects.

The mean k-factor is used to correct the available MTL data from 1990 to 1999 for the Heligoland station and from 1844 to 1917 for the Cuxhaven station. Figure 5 shows the resulting monthly and annual MSL time series together with a fitted second order polynomial function providing the smallest MSE of the considered parametric approaches mentioned in Sect. 2. The Heligoland station shows a significant positive acceleration of $0.18 \pm 0.05 \mathrm{~mm} \mathrm{a}^{-2}$ (two times the quadratic coefficient of the second order polynomial fit), a linear long-term trend of $1.85 \pm 0.42 \mathrm{~mm} \mathrm{a}^{-1}$ for the entire period and a linear trend of $8.50 \pm 2.32 \mathrm{~mm} \mathrm{a}^{-1}$ for the reduced period since 1993 (all quoted errors are one $\sigma$ standard errors). The Cuxhaven MSL time series shows a weak negative acceleration for the entire period, which is consistent with the results found for most of the European gauges providing long records by Woodworth et al. (2009a). The estimated linear trend is $2.03 \pm 0.08 \mathrm{~mm} \mathrm{a}^{-1}$ for the entire period, $1.75 \pm 0.17 \mathrm{~mm} \mathrm{a}^{-1}$ for the twentieth century, $1.81 \pm 0.44 \mathrm{~mm} \mathrm{a}^{-1}$ for the period since 1953 and $6.44 \pm 3.05 \mathrm{~mm} \mathrm{a}^{-1}$ for the reduced period from 1993 to 

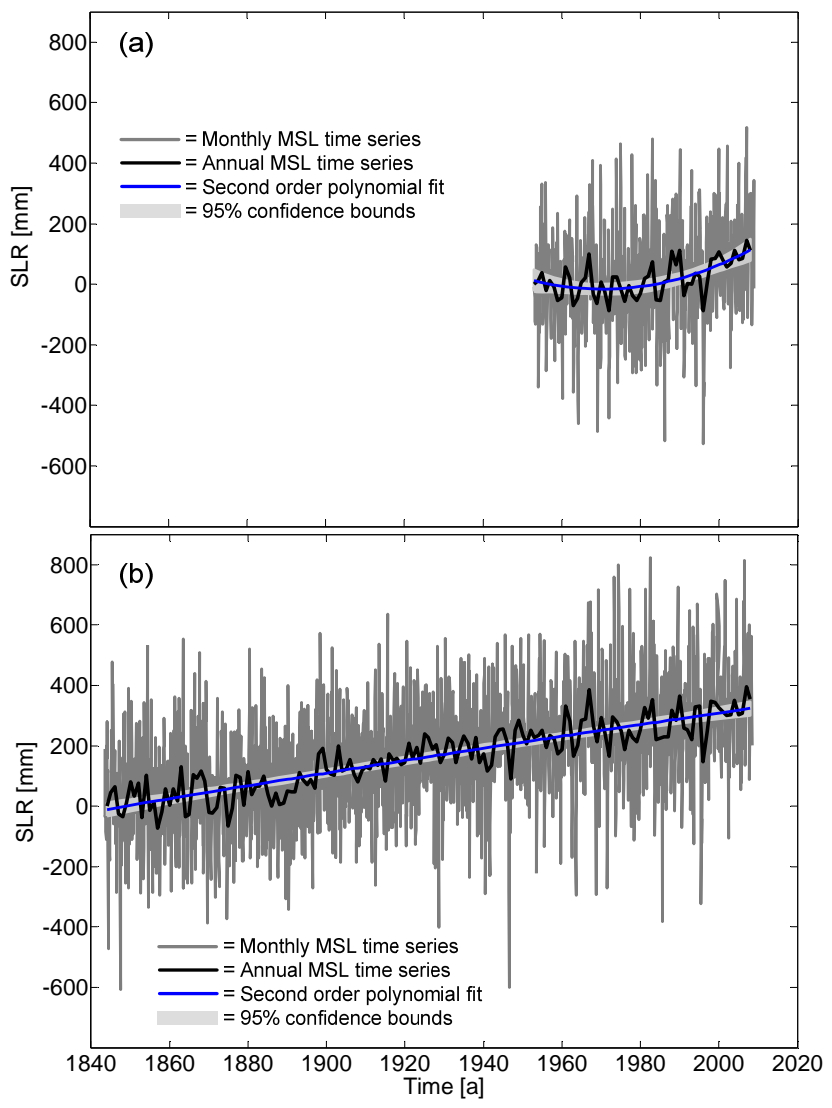

Fig. 5. Monthly and annual MSL time series for the Heligoland tide gauge (a) and the Cuxhaven tide gauge (b) and results from parametric fitting.

2008. The linear trends for the period covered by both tide gauge records (1953 to 2008) are almost equal, which indicates the quality of the data. Furthermore, conspicuous high or low annual MSL values in general occur at both gauges at the same time. For example the low value for the year 1996, due to offshore winds and very little precipitation and runoff, or the high value for the year 1967, a year with many storm surges. The trend found for the twentieth century from the Cuxhaven time series differs slightly from that found by Woodworth et al. (2009b). He derived a linear trend of $1.4 \pm 0.2 \mathrm{~mm} \mathrm{a}^{-1}$ from investigating a large number of tide gauges around the UK. The trends estimated for the short period from 1993 to 2008 are more than two times the trend found from global altimetry data for almost the same period (Beckley et al., 2007). This is an interesting result, but 16 years are a very short period to analyse high variability sea level time series as found in the German North Sea region.

The results for the non-linear data adaptive smoothing using SSA with an embedding dimension of 11 years for the Heligoland time series and of 33 years for the Cuxhaven time series and the resulting annual rates of SLR are shown in Fig. 6. The results from the Cuxhaven station (Fig. $6 \mathrm{c}$ and
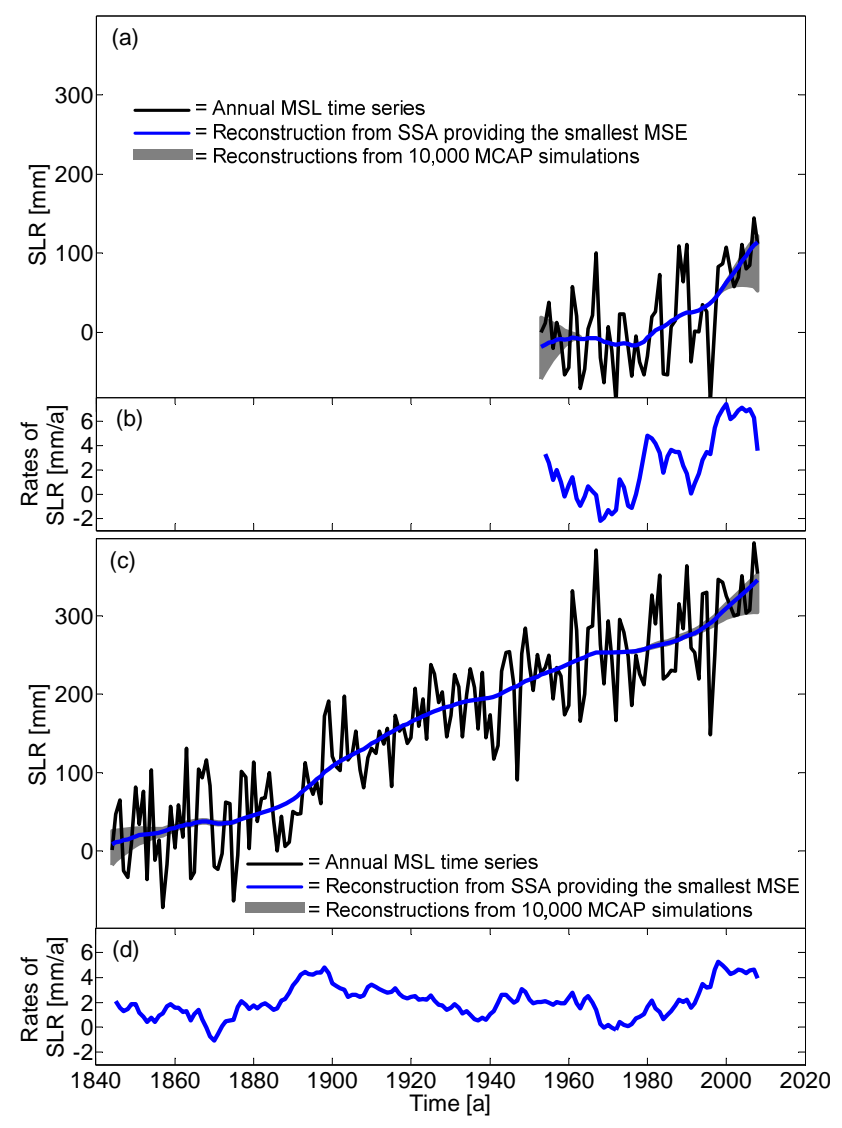

Fig. 6. Results from non-linear smoothing using SSA in combination with MCAP and annual rates of SLR estimated as the first deviation of the reconstruction providing the smallest MSE for the Heligoland MSL time series ( $\mathbf{a}$ and $\mathbf{b}$ ) and the Cuxhaven MSL time series (c and d).

d) point to a period of strong positive acceleration of SLR at the end of the 19th century, to a negative acceleration in subsequent years and to a period of almost no SLR around the 1970s with subsequent positive acceleration. High rates are observed for the period around 1900 and the highest rates of about $5 \mathrm{~mm} \mathrm{a}^{-1}$ are estimated for the year 2000 . The inflection point at the end of the 19th century is remarkably close to observed inflection points around 1880 at the Liverpool tide gauge (Woodworth, 1999) and around 1890 at the Brest tide gauge (Wöppelmann et al., 2006).

The post 1970 acceleration is approved by the results from analysing the shorter MSL time series of the Heligoland station (Fig. 6a and b). The observed rates around 2000 from the Heligoland sea level time series are even higher than those found from the Cuxhaven time series, but clearly decrease in the recent years. Note that the annual rates were estimated from the SSA reconstruction providing the smallest MSE and that the uncertainties increase near the boundaries.

The results from analysing the recently updated global sea level reconstruction of Church and White (2006) are shown 


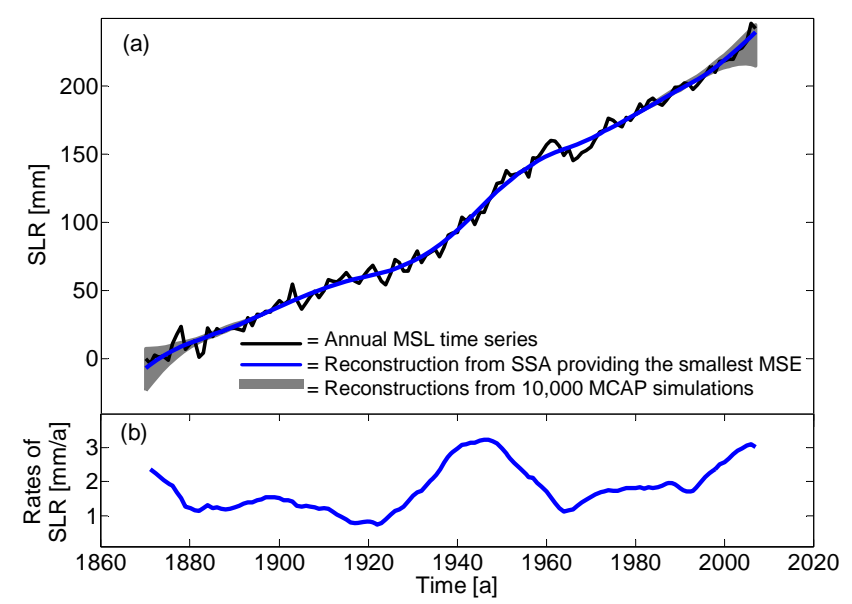

Fig. 7. Results from non-linear smoothing using SSA in combination with MCAP and annual rates of SLR estimated as the first deviation of the reconstruction providing the smallest MSE for a worldwide sea level reconstruction from 1870 to 2007.

in Fig. 7. The time series provides data from 1870 to 2007. Thus, an embedding dimension of 28 years has been used for the SSA analysis. The smoothed time series shows remarkably different patterns of SLR than the sea level time series from the German North Sea area. A positive acceleration occurred at the end of the 1930s, leading to high rates of SLR around 1940. A following negative acceleration led to low rates for the period after 1960 and rates are increasing again in the recent years.

Figure 8 clearly approves the existence of different patterns of SLR. It shows the difference $\Delta$ between the estimated annual rates of SLR for the Cuxhaven station (Fig. 6d) and the annual rates of SLR estimated from the global reconstruction (Fig. 7b). The resulting time series highlights a stronger SLR in the German North Sea area for a period covering some decades at the end of the 19th century and the beginning of the 20th century and for another period covering the last ten to fifteen years. For both periods the annual rates of SLR in the German North Sea area are found be up to $3 \mathrm{~mm} \mathrm{a}^{-1}$ higher than those estimated from a global sea level reconstruction.

The correlation coefficient between the annual rates of SLR from the Cuxhaven station and the Heligoland station is found to be $r=0.71$ for the overlapping period from 1953 to 2008. The correlation between the annual rates of SLR from the Cuxhaven station and the annual rates estimated from the global sea level reconstruction is comparably weak. The correlation coefficient for the overlapping period from 1870 to 2007 is found to be $r=0.33$.

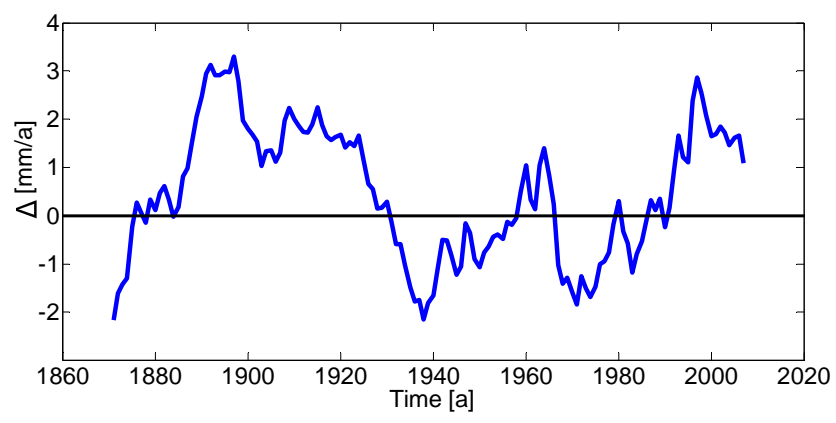

Fig. 8. Difference $\Delta$ for the period of 1870 to 2007 between the annual rates of SLR estimated from the Cuxhaven MSL time series and the annual rates of SLR estimated from a global sea level reconstruction.

\section{Conclusions and outline}

In this paper, advanced methods to generate and analyse mean sea level time series are introduced. The presented modification of the k-factor method and the MCAP approach for padding non stationary sea level time series including uncertainty assessment contribute to overcome an existing lack of knowledge in analysing mean sea level time series, especially in shallow seas. The results from analysing the available data sets from two relevant tide gauges in the German North Sea highlight a post 1970 acceleration of SLR, which has not been reported before and which has obviously declined in recent years. The comparison between the German North Sea sea level time series and a global sea level reconstruction clearly reveals the existence of different patterns of SLR. A stronger SLR in the German North Sea area is detected for a period covering some decades starting at the end of the 19th century and for another period covering the last ten to fifteen years. However, coastal structures along the German North Sea coastline are well-conditioned and to some extend prepared for an expected SLR. In addition, the sea level is part of a complex system undergoing natural variability and there are still considerable uncertainties in the results.

Nevertheless, the study also indicates the necessity of further research in the field of sea level analysis and observation. Uncertainties might be reduced by applying the results of GPS measurements to improve the rates of vertical land movements considered in the sea level analyses (e.g. Wöppelmann et al., 2007, 2009). Furthermore, a reduction of variability of the time series will result in an error reduction. This might be done by considering more high quality MSL time series from German North Sea tide gauges or by quantifying the impacts of stochastic meteorological processes such as wind setup or air pressure. All of the mentioned work areas are subject to actual scientific efforts in Germany. More and more tide gauges are equipped with GPS by the Federal Agency of Hydrology (BfG, Koblenz). 
A time consuming digitisation exercise is going on and partially fulfilled at the University of Siegen. This is to allow the consideration of more high quality MSL time series to improve the results presented in this paper, e.g. by estimating a synthetic time series for the entire German North Sea area. The impact of wind set up and air pressure will be quantified in close cooperation with oceanographers from the Federal Maritime and Hydrographic Agency (BSH, Hamburg).

Finally, the presented results highlight the need for further research to improve regional climate models or regional sea level projections respectively. It is shown that regional patterns of SLR in the German North Sea area are not consistent with global patterns of SLR. Thus, the consideration of global SLR scenarios, as published for example by the IPCC, for regional planning purposes must be denoted as an interim solution. The results presented in this paper and the results expected after finishing the digitisation exercise will contribute to the verification of models for the German North Sea area.

Acknowledgements. We highly acknowledge the German Coastal Engineering Research Council (KFKI) and the German Federal Ministry of Education and Research (BMBF) for providing the opportunity to overcome an existing lack of knowledge in the field of mean sea level research in Germany by funding the research project "AMSeL - Mean Sea Level and Tidal Analysis at the German North Sea Coastline”. Thanks to Sylvin Müller-Navarra from the BSH in Hamburg for his professional comments on our work and to the anonymous reviewer helping to improve the quality of this paper.

Edited by: T. Glade

Reviewed by: S. Müller-Navarra and another anonymous referee

\section{References}

Beckley, B. D., Lemoine, F. G., Luthcke, S. B., Ray, R. D., and Zelensky, N. P.: A reassessment of global and regional mean sea level trends from TOPEX and Jason-1 altimetry based on revised reference frame and orbits, Geophys. Res. Lett., 34, L14608, doi:10.1029/2007GL030002, 2007.

Box, G. E. P. und Jenkins, G. M.: Time Series Analysis- forecasting and control, Holden-Day, London, 1976.

Chen, H. L. and Rao, A. R.: Testing Hydrologic Time Series for Stationarity, J. Hydrologic Eng., 7(2), 129-136, doi:10.1061/(ASCE)1084-0699(2002)7:2(129), 2002.

Church, J. A. and White, N. J.: A 20th century acceleration in global sea-level rise, Geophys. Res. Lett., 33, L01602, doi:10.1029/2005GL024826, 2006.

Church, J. A., White, N. J., Aarup, T., Wilson, S. W., Woodworth, P. L., Domingues, C. M., Hunter, J. R., and Lambeck, K.: Understanding global sea levels: past, present and future, Sustain. Sci., 3(1), 9-22, doi:10.1007/s11625-008-0042-4, 2008.

Dietrich, G.: Ozeanographisch-meteorologische Einflüsse auf Wasserstandsänderungen des Meeres am Beispiel der Pegelbeobachtungen von Esbjerg, Die Küste, 2/2, 130-157, 1954.
Führböter, A. and Jensen, J.: Säkularänderungen der mittleren Tidewasserstände in der Deutschen Bucht, Die Küste, 42, 78-100, 1985.

Ghil, M., Allen, M. R., Dettinger, M. D., Ide, K., Kondrashov, D., Mann, M. E., Robertson, A. W., Saunders, A., Tian, Y., Varadi, F., and Yiou, P.: Advanced spectral methods for climatic time series, Rev. Geophys., 40(1), 1003, doi:10.1029/2000RG000092, 2002.

Gönnert, G., Isert, K., Giese, H., and Plüß, A.: Charakterisierung der Tidekurve, Die Küste, 68, 101-141, 2004.

Golyandina, N., Nekrutkin, K., and Zhiglëiìavskiæi, A. A.: Analysis of time series structure, SSA and related techniques, Chapman \& Hall/CRC (Monographs on statistics and applied probability, 90), Boca Raton, Florida, 2001.

Grinsted, A., Moore, J. C., and Jevrejeva, S.: Reconstructing sea level from paleo and projected temperatures 200 to $2100 \mathrm{AD}$, Clim. Dynam., published online first, doi:10.1007/s00382-0080507-2, 2009.

Holgate, S. J.: On the decadal rates of sea level change during the twentieth century, Geophys. Res. Lett., 34, L01602, doi:10.1029/2006GL028492, 2007.

Holgate, S. J., Jevrejeva, S., Woodworth, P. L., and Brewer, S. C.: Comment on: "A Semi-Emprical Approach to Projecting Future Sea-Level Rise”, Empirical, Science, 317(5846), 18661867, doi:10.1126/science.1140942, 2007.

Jansen, E., Overpeck, J., Briffa, K. R., Duplessy, J.-C., Joos, F., Masson-Delmotte, V., Olago, D., Otto-Bliesner, B., Peltier, W. R., Rahmstorf, S., Ramesh, R., Raynaud, D., Rind, D., Solomina, O., Villalba, R., and Zhang, D.: Palaeoclimate, in: Climate Change 2007: The Physical Science Basis, Contribution of Working Group I to the Fourth Assessment Report of the Intergovernmental Panel on Climate Change, edited by: Solomon, S., Qin, D., Manning, M., Chen, Z., Marquis, M., Averyt, K. B., Tignor, M., and Miller, H. L., Cambridge University Press, Cambridge, United Kingdom and New York, NY, USA, 2007.

Jensen, J. and Mudersbach, C.: Zeitliche Änderungen in den Wasserstandszeitreihen an den Deutschen Küsten, in: Berichte zur Deutschen Landeskunde, Themenheft: Küstenszenarien, Band 81, Heft 2, pp. 99-112, edited by: Glaser, R., Schenk, W., Vogt, J., Wießner, R., Zepp, H., und Wardenga, U., Selbstverlag Deutsche Akademie für Landeskunde e.V., Leipzig, 2007.

Jevrejeva, S., Grinsted, A., Moore, J. C., and Holgate, S.: Nonlinear trends and multiyear cycles in sea level records, J. Geophys. Res. 111, C09012, doi:10.1029/2005JC003229, 2006.

Jevrejeva, S., Moore, J. C., Grinsted, A., and Woodworth, P. L.: Recent global sea level acceleration started over 200 years ago?, Geophys. Res. Lett., 35, L08715, doi:10.1029/2008GL033611, 2008.

Lassen, H.: Örtliche und zeitliche Variationen des Meeresspiegels in der südöstlichen Nordsee, Die Küste, 50, 65-96, 1989.

Lentz, H.: Fluth und Ebbe und die Wirkungen des Windes auf den Meeresspiegel, Otto Meissner, Hamburg, 1879.

Mann, H. B.: Nonparametric Test Against Trend, Econometrica, Journal of the Econometric Society, 13, 245-259, 1945.

Mann, M. E.: On smoothing potentially non-stationary climate time series, Geophys. Res. Lett., 31, L07214, doi:10.1029/2004GL019569, 2004.

Mann, M. E.: Smoothing of climate time series revisited, Geophys. Res. Lett., 35, L16708, doi:10.1029/2008GL034716, 2008. 
Meehl, G. A., Stocker, T. F., Collins, W. D., Friedlingstein, P., Gaye, A. T., Gregory, J. M., Kitoh, A., Knutti, R., Murphy, J. M., Noda, A., Raper, S. C. B., Watterson, I. G., Weaver, A. J., and Zhao, Z.-C.: Global Climate Projections, in: Climate Change 2007: The Physical Science Basis, Contribution of Working Group I to the Fourth Assessment Report of the Intergovernmental Panel on Climate Change, edited by: Solomon, S., Qin, D., Manning, M., Chen, Z., Marquis, M., Averyt, K. B., Tignor, M., and Miller, H. L., Cambridge University Press, Cambridge, United Kingdom and New York, NY, USA, 2007.

Mudersbach, C. and Jensen, J.: Non-stationarities in time series and its integration in extreme value statistics for risk management issues, Proc. of the 31st Int. Conf. on Coastal Engineering (ICCE), Hamburg, Germany, 2008.

Müller-Navarra, S. H. and Giese, H.: Improvements of an empirical model to forecast wind surge in the German Bight, DHZ, 51(4), 385-405, 1999.

Peltier, W. R.: Global Glacial Isostasy and the Surface of the Ice-Age Earth: The ICE-5G(VM2) model and GRACE, Ann. Rev. Earth. Planet. Sci., 32, 111-149, doi:10.1146/annurev.earth.32.082503.144359, 2004.

Pugh, D.: Changing Sea Levels: Effects of Tides, Weather and Climate, 265 pp., Cambridge Univ. Press, New York, 2004.

Rahmstorf, S.: A Semi-Empirical Approach to Projecting Future Sea-Level Rise, Science, 315(5810), 368-370, doi:10.1126/science.1135456, 2007.

Rahmstorf, S., Cazenave, A., Church, J. A., Hansen, J. E., Keeling, R. F., Parker, D. E., and Somerville, R. C. J.: Recent Climate Observations Compared to Projections, Science, 316, 709, doi:10.1126/science.1136843, 2007.

Rohde, H.: Die Pegel auf Helgoland, Die Küste, 49, 125-141,1990.

Schöne, T., Schön, N., and Thaller, D.: IGS Tide Gauge Benchmark Monitoring Pilot Project (TIGA): scientific benefits, J. Geodesy, 83(3/4), 249-261, doi:10.1007/s00190-008-0269-y, 2009.

von Storch, H., Zorita, E., and González-Rouco, F.: Relationship between global mean sea-level and global mean temperature in a climate simulation of the past millennium, Ocean Dynam., 58(3/4), 227-236, doi:10.1007/s10236-008-0142-9, 2008.

Töppe, A. and Brockmann, T.: Tidewasserstände am Pegel Bensersiel seit 1825. Mitteilungen des Leichtweiss-Instituts für Wasserbau, H. 120, Braunschweig, 1992.
Trenberth, K. E., Jones, P. D., Ambenje, P., Bojariu, R., Easterling, D., Klein Tank, A., Parker, D., Rahimzadeh, F., Renwick, J. A., Rusticucci, M., Soden, B., and Zhai, P.: Observations: Surface and Atmospheric Climate Change, in: Climate Change 2007: The Physical Science Basis, Contribution of Working Group I to the Fourth Assessment Report of the Intergovernmental Panel on Climate Change, edited by: Solomon, S., Qin, D., Manning, M., Chen, Z., Marquis, M., Averyt, K. B., Tignor, M., and Miller, H. L., Cambridge University Press, Cambridge, United Kingdom and New York, NY, USA, 2007.

Van Gelder, P. H. A. J. M., Mai, C. V., Wang, W., Shams, G., Rajabalinejad, M., and Burgmeijer, M.: Data management of extreme marine and coastal hydro-meteorological events, J. Hyd. Res., 46(2), 191-210, 2008.

Wahl, T., Jensen, J., and Frank, T.: Changing Sea Level and Tidal Dynamics at the German North Sea Coastline, Proc. of the Coastal Cities Summit 2008 - Values and Vulnerabilities, St. Petersburg, Florida, USA, 2008.

White, N. J., Church, J. A., and Gregory, J. M.: Coastal and global averaged sea level rise for 1950 to 2000 , Geophys. Res. Lett., 32, L01601, doi:10.1029/2004GL021391, 2005.

Woodworth, P. L.: High waters at Liverpool since 1768: the UK's longest sea level record, Geophys. Res. Lett., 26(11), 1589-1592, 1999.

Woodworth, P. L., White, N. J., Jevrejeva, S., Holgate, S. J., and Gehrels, W. R.: Evidence for the accelerations of sea level on multi-decade and century timescales, Int. J. Climatol., 29(6), 777-789, doi:10.1002/joc.1771, 2009a.

Woodworth, P. L., Teferle, F. N., Bingley, R. M., Shennan, I., and Williams, S. D. P.: Trends in UK mean sea level revisited, Geophys. J. Int., 176(22), 19-30, doi:10.1111/j.1365246X.2008.03942.x, 2009b.

Wöppelmann, G., Pouvreau, N., and Simon, B.: Brest sea level record: A time series construction back to the early eighteenth century, Ocean Dynamics, 56(5-6), 487-497, doi:10.1007/s10236-005-0044-z, 2006.

Wöppelmann, G., Martin-Miguez, B., Bouin, M.-N., and Altamimi, Z.: Geocentric sea-level trend estimates from GPS analyses at relevant tide gauges world-wide, Global Planet. Change, 57, 396-406, 2007.

Wöppelmann, G., Letetrel, C., Santamaria, A., Bouin, M.-N., Collilieux, X., Altamimi, Z., Williams, S. D. P., and MartinMiguez, B.: Rates of sea-level change over the past century in a geocentric reference frame, Geophys. Res. Lett., 36, L12607, doi:10.1029/2009GL038720, 2009. 